\title{
A New Development in Front Group Strategy: The Social Aspects Public Relations Organization (SAPRO)
}

\author{
Rachel Pietracatella ${ }^{\dagger}$ and Danielle Brady ${ }^{*+}$ \\ School of Arts and Humanities, Edith Cowan University, Mt Lawley, WA, Australia
}

Increased pressure on risk industries to reduce their negative impact on society has resulted in an increasing volume of "risk" and "responsibility" communications from interest groups known as Social Aspects Public Relations Organizations (SAPROs). SAPROs have been criticized for being the "front groups" of risk industries (e.g., the tobacco, gambling, sugar, and alcohol industries). Operating within the neoliberal policy framework, SAPROs seek to forestall regulation and prioritize industry profits over public health. Building on risk industry research from the public health sphere, this article examines the SAPRO phenomenon and situates it in the political public relations (PR) literature. Specifically, it considers how SAPROs perform an indirect lobbying function on

OPEN ACCESS

Edited by:

William Dinan,

University of Stirling, United Kingdom

Reviewed by:

Yik Chan Chin,

Xi'an Jiaotong-Liverpool

University, China

David Miller,

University of Bristol, United Kingdom

*Correspondence:

Danielle Brady

d.brady@ecu.edu.au

tThese authors have contributed equally to this work

Specialty section:

This article was submitted to Political Communication,

a section of the journal

Frontiers in Communication

Received: 13 August 2019

Accepted: 24 March 2020

Published: 21 April 2020

Citation:

Pietracatella $R$ and Brady D (2020) A New Development in Front Group

Strategy: The Social Aspects Public

Relations Organization (SAPRO).

Front. Commun. 5:24.

doi: 10.3389/fcomm.2020.00024 behalf of their funding industries. Using DrinkWise as an example of an alcohol SAPRO, this article shows that SAPROs represent a novel development in front group strategy and examines how this development intersects with neoliberalism. This article also argues that SAPROs are deployed by risk industries to hegemonically promote the idea of personal responsibility and that their indirect lobbying function may be necessary to the continuance of neoliberal policies.

Keywords: SAPRO, social aspects public relations organization, risk communication, indirect lobbying, critical PR, alcohol, CSR

\section{INTRODUCTION}

Public health advocates have called for urgent research to be undertaken to determine whether the global alcohol industry is using "front group" and public relations (PR) tactics similar to those used by the tobacco industry to create a more favorable regulatory and legislative environment at the expense of public health (Mialon and McCambridge, 2018). The 1998 United States (US) Master Settlement Agreement (MSA) required the release of tobacco and alcohol industry documents. The ensuing analysis of these documents revealed that when confronted with potential profit reducing regulation, industry players responded with combative measures, including the use of front groups, but claimed that the purpose of these measures was Corporate Social Responsibility (CSR) (Apollonio and Bero, 2007a,b; McDaniel et al., 2008; Brownell and Warner, 2009).

Organizations that obscure their purpose and/or do not disclose their funding interests are considered front groups. Fitzpatrick and Palenchar (2006, p.203) defined front groups as "controversial PR techniques used by organizations to influence public opinion and public policy on behalf of undisclosed special interests." This article examines special interest groups openly funded by the alcohol industry that present their purpose as CSR while promoting the continued self-regulation of their funding industries. The health literature describes these special interest groups as Social Aspects Public Relations Organizations (SAPROs) (Babor, 2009; Miller et al., 2011; Babor and Robaina, 2013; Adams and Livingstone, 2015; Petticrew et al., 2018a,b). 
This article argues that risk industries (e.g., the gambling, sugar and alcohol industries) use the "third-party technique," often credited to Edward Bernays, to disseminate self-interested messages (Fitzpatrick and Palenchar, 2006). This article also contends that seemingly independent organizations are being used to perform an indirect lobbying function on behalf of their industry funders to influence legislators. To investigate the relationship between this novel development in PR and neoliberalism, we define neoliberalism as the practical implementation of policies that relocate power from political to economic processes (Thorson, 2010). This rule of the market champions individual freedom with minimal state intervention in business and is characterized through privatization, the deregulation of markets and a shift away from state welfare provision. We note it can be defined as an ideology as well this aforementioned loose set of practices that dominate western normative and practical politics between the state and its external environment. Using this definition, this article argues that current neoliberal policies encourage the establishment of SAPROs and allow their targeted education strategies to triumph over public health evidence-based and society-wide strategies that seek to reduce harms. In conjunction with other forms of corporate political influence, SAPROs reinforce and perpetuate conditions that allow business and corporations to be most free of government regulation and are thus championed and legitimized by politicians with neoliberal ideals. SAPROs are therefore complementary to neoliberalism, combining in such a way as to emphasize the qualities of each. SAPROs may even be necessary to the continued acceptance of neoliberal policies, as they play a strategic role in managing public perceptions of social problems by playing into and valorizing notions of individual freedom and choice.

SAPROs present themselves as independent and benevolent organizations that are concerned with the mitigation of negative social aspects of potentially harmful products. However, despite their benevolent exterior, they should be viewed negatively, as a corporate PR strategy to block meaningful harm minimization campaigns (Anderson, 2004; Miller et al., 2009; Adams and Livingstone, 2015; Cowlishaw and Thomas, 2018; Petticrew et al., 2018b). The presence of gambling SAPROs is not yet strong (Adams, 2016, p. 99; Adams and Livingstone, 2015); however, alcohol SAPROs have been gaining increasing prominence since the 1980s. Unlike other third-party industry groups (e.g., trade associations), SAPROs have greater direct overlap with public health activities (Babor and Robaina, 2013). SAPROs were ostensibly created by alcohol companies as CSR vehicles (Houghton, 1998; Anderson, 2004; Babor and Robaina, 2013). Anderson (2004) was one of the first researchers to draw attention to these groups. He referred to them as "social aspects organisations" and noted that these alcohol industry-funded organizations focus on drinking patterns rather than volumes of consumption, describe personal responsibility as a learned behavior, are involved in policy deliberations, advocate for the self-regulation of alcohol marketing and comment on the overall benefits of alcohol consumption to society (Anderson, 2004, p. 1377).

SAPROs appeared during a period in which competition had become a normative principle that extended well-beyond markets of exchange. Domains such as health, education and scientific research, which were once state directed, had become subject to market-like processes of evaluation during the rise of neoliberalism or what Davies $(2017$, p. 6) calls "the disenchantment of politics by economics." According to Biebricher (2015), the reshaping of structures in response to the 2007 economic crisis challenged democracy. Biebricher (2015, p. 257) further contended that neoliberal theory must be understood as a body of thought that revised and revitalized elements of the classical liberal agenda in response to perceptions about the perceived crisis and global governance. Neoliberalism positions freedom as an overarching social value, rejects industry regulation and high taxation and posits that public services should be subjected to market competition. A strong government is only required to facilitate global commerce, protect private property through law enforcement and maintain military and defense services. Due to the reduced role of government, it is the market that must educate citizens of the potential harms of products. Walker (2012, p. 561) notes that corporations can benefit from this transformed institutional environment by taking a proactive role in political strategy and initiating grassroots and constituency building efforts to supplement inhouse public and government affairs operations.

The alcohol (Miller et al., 2011; Avery et al., 2016) and the gambling industries (Cowlishaw and Thomas, 2018) have vested interests in SAPROs. Thus, rather than seeking to reduce harms, critical research suggests that a key goal of these institutions is to avoid government regulation and ensure the continuance of industry self-regulation. Further, SAPROs seek to protect the surplus profits generated by problem and harmful consumption (Adams and Livingstone, 2015). According to the surplus thesis, due to the globalization of risk industries, billions of dollars in surplus industry profits can be allocated to PR strategies and lobbying efforts. Such surplus profits might not be available if the risk industries were subject to harm alleviating, societywide regulation.

Despite claims that they operate in the public interest and remain independent of their funders, alcohol SAPROs have been found to advocate for their funding industries (Carah and van Horen, 2011; Pietracatella and Brady, 2016; Miller et al., 2018). The type of pro-consumption lobbying in which SAPROs invest has also been found to block actual harm reduction (Miller et al., 2018). The risk industries behind SAPROs deny that SAPROs are PR organizations and claim that SAPROs perform CSR activities for their industries and that the resulting reputational benefits should grant them a seat at the policy table (Miller et al., 2011; Avery et al., 2016). However, Mialon and McCambridge (2018) undertook a systematic review of alcohol industry CSR initiatives and noted that the education and social marketing initiatives had a number of possible adverse effects on public health.

We view SAPROs as corporate political PR; and not CSR, and thus situate it in the PR, political communication and political science literature. Strömbäck and Kiousis (2011) call for filling the gap with theory and research at the convergence of the three disciplines and draw attention to the relative novelty of political PR as a research field. This is despite the importance of political PR itself, and its key concept of persuading and informing target audiences. More recently, Ingenhoff and 
Marschlich (2019) systematically reviewed corporate diplomacy and political CSR from journals from the fields of PR, public diplomacy, general management and business ethics, providing a foundation for empirical analysis of the political communication of multinational corporations.

To date, relatively little empirical research has been conducted on SAPROs. Of the studies conducted, some have focused on the alcohol SAPRO DrinkWise. However, the results of studies on SAPROs in other risk industries (e.g., the tobacco industry) could be applied to the alcohol industry by cross-case logic, as it is likely that in similar circumstances, other industries would use similar tactics for similar reasons (Brownell and Warner, 2009; Adams, 2016). This article contends that while communications by SAPROs may resemble CSR communications, due to their funding sources, any such communications comprise corporate political activities. It is clear that risk industries learn from each other and often engage the same PR and legal firms to organize political activities (Apollonio and Bero, 2007a, p. 419).

Using DrinkWise as an example of a SAPRO, this article begins by examining the intersection of SAPROs with neoliberalism. It then addresses public health claims that SAPROs are front groups that engage in $\mathrm{PR}$ activities on behalf of risk industries. This critical examination of the establishment and effects of SAPROs shows that they engage in two related roles; they indirectly lobby on behalf of their industries and they disseminate an ideology that supports a neoliberal policy framework.

\section{SAPROS AND NEOLIBERALISM}

\section{CSR: Adopting a Market Approach to Solve Social Issues}

Rather than be subjected to government regulation, industry prefers to self-regulate or facilitate market solutions to social issues. In a neoliberal policy environment, a desire by industry to adopt this approach and an absence of state intervention creates a vacuum that CSR and CSR-like organizations (e.g., SAPROs) seek to fill. Adams (2016, p. 96) argues that risk industries "have co-opted the language, practices and reputation of CSR to project an aura of ethical business practice" and that "CSR has provided a means of holding back health advocacy 'wolves at the door' and of maintaining positive engagement with employees." Taking a more positive view, Scherer and Palazzo (2011) argue that in a global economy, organizations and industries become politicized, often filling a regulatory vacuum and therefore transcend mainstream perspectives of CSR as compliance to societal expectations and notions of economic CSR. They place this political activity under the new rubric of political CSR that can see firms engage in activities once provided by the state, including public health activities.

The argument that CSR is complimentary to neoliberalism is not new (Kinderman, 2011). In a neoliberal policy framework, to ensure that every aspect of society conforms to the dictates of the marketplace, public health communication is commodified. Despite research and commentary that contends that SAPROs do not perform substantive harm reduction activities, new research on the CSR activities of alcohol companies has shown that $<2 \%$ of the CSR activities conducted in Europe have produced positive health effects and that while the efforts of these companies are unlikely to contribute to the targets of the World Health Organization (WHO), they "may have a publicrelations advantage for the alcohol industry" (Babor et al., 2018, p. 8). In an attempt to explain the rise of CSR, Kinderman (2015, p. 109) used Grayson and Nelson's definition of these particular special interest groups to underscore what he terms "national CSR" for national level business-led non-government organizations (i.e., coalitions that "carry the moniker" of CSR). Kinderman found that, while correlating with neoliberalism, CSR was not coterminous with globalization (Kinderman, 2015) and described it as a collaborative action that has been raised to meet broader business and societal needs.

SAPROs can be viewed as a manifestation of a market approach to solving social issues and are presented as such by the organizations themselves. When normal market processes do not solve social problems, "a facilitated market solution, a deliberate assembly of stakeholders led by a private professional organization to solve a specific social problem," can be mobilized (Williams and Perraut, 2008, p. 4). Governments themselves may even "turn to" private mediators for solutions to societal problems, as these types of intermediary organizations are viewed as progressive innovation providers that are unbounded by "sometimes outdated" apparatus of the government (Williams and Perraut, 2008, p. 5).

The potential CSR contributions of non-risk industries should be acknowledged in circumstances in which no significant conflicts of interest exist between profits and public interest. However, the concept of CSR continues to be problematic due to the lack of a shared definition and, as L'Etang (1994) has noted, CSR has become a PR tool. Public health perceives alcohol industry CSR activities as largely instrumental and/or political (Mialon and McCambridge, 2018). Mialon and McCambridge (2018) adopted Garriga and Mele's (2004) definition of instrumental CSR, which states that instrumental CSR is used to advance economic objectives. Conversely, political CSR is used to influence policy and extend power within society. SAPROs represent what Grayson and Nelson (2013) have termed "business-led corporate responsibility coalitions."

In summary, four main issues underscore public health fears about the adoption of a market approach to alcohol CSR: (1) that the alcohol industry's facilitated CSR attempts fall short of the WHO's call for CSR that has been proven to be effective; (2) that CSR attempts could have negative effects; (3) that a commonsense conflict of interest exists between profits and public interest; and (4) that the marketing of the industry is self-regulated.

\section{DrinkWise: Adopting a Market Approach to Reduce Alcohol-Related Harms in Australia} DrinkWise, an Australian alcohol SAPRO, has adopted a facilitated market solution to address the harms associated with alcohol. The establishment of such new governance structures shows the relevance of the neoliberal context. Following sustained negative media coverage of the societal impact of 
alcohol-related harms, in neoliberal deference to the market, the Australian Government matched the alcohol industry's contribution of \$5 million to establish DrinkWise in 2005 (Hall and Room, 2006). Viewed with skepticism by public health researchers, particularly in relation to its claim to be independent, the establishment of DrinkWise was as much a political move to show the industry's ability to provide a market solution to a social issue than a move to reduce real harms. The cash subsidy is evidence of an interventionist state working to prevent the regulation of markets.

After the launch of DrinkWise's first PR campaign, several DrinkWise executives were quoted in the media, suggesting that the organization was adopting a market approach to solve a social problem. Chris Watters, the Chief Executive Officer of DrinkWise at the time, argued against the society-wide approach that had been suggested to address the issue and voiced his opposition to any "fiddling with [the] alcohol tax" (Sweet, 2009). Noel Turnbull, the then DrinkWise Director and a former director of one of Australia's largest PR companies, Turnbull Fox Phillips, criticized government/state approaches to harm reduction and contended that a market approach should be adopted to solve the issue in several public texts (Kerr, 2009; Miller, 2009; Turnbull, 2014). In a national newspaper article, Turnbull stated that adopting a market approach to address this social issue would be better than the government's approach for two reasons (Kerr, 2009). First, Turnbull contended that a market approach should be adopted on the grounds of efficiency. This argument reflects the neoliberal position that state interference creates stagnation, waste and inefficiency. Second, Turnbull contended that the market (i.e., DrinkWise) is better equipped to solve this social issue due to the short sightedness of governments and electoral cycles. He criticized the government's inclination to direct social marketing to the wrong targets, stating: "There are alternatives available which treat people as citizens capable of changing behavior without draconian regulation and punitive taxation" (Kerr, 2009: para 5). Turnbull further contended that a market approach would protect the freedom of the individual. Neoliberal thinking relies on the "assumption that individual freedoms are guaranteed by freedom of the market and trade" (Harvey, 2005, p. 7). Turnbull veered toward market fundamentalism, arguing that because of its need for legitimacy, industry is better positioned than the government to genuinely eliminate alcohol problems, as industry can adopt a long-term social marketing approach.

Unlike the government, SAPROS are limited to the dissemination of rhetoric, as they have no powers of enforcement. SAPROs disseminate responsibility communications that reduce the legitimacy gap between CSR claims and the actual outcomes to which Turnbull refers. When the legitimacy of a company (or industry in this case) is challenged and it fails to instrumentally adapt to the prevailing notions of legitimacy, other options in closing this gap fall to PR efforts. According to Dowling and Pfeffer (1975) communication options can either (1) alter that definition of social legitimacy or (2) use communication to "become identified with symbols values or institutions which have a strong base of legitimacy" (Dowling and Pfeffer, 1975, p. 127). Interestingly, SAPROs are positioned to reduce the gap between claims of the benefits of neoliberal practices and the actual results of the practices. For neoliberal political practices to continue to be used to pursue certain interests, the gap must (at least rhetorically) be filled.

The United Kingdom (UK) alcohol SAPRO, DrinkAware, was established in 2006 following a memorandum of understanding between the Portman Group of alcohol producers and various UK government agencies (McCambridge et al., 2014, p. 519). Like DrinkWise in Australia, DrinkAware UK is funded by alcohol companies but run by a board comprised of industry, public health and community directors. McCambridge et al. (2014) compared DrinkWise and DrinkAware, citing them as examples of alcohol SAPROs that have been established as a market approach to reduce harms and noting the recent proliferation of such organizations. The practices and effects of SAPROs are considered in the following section. Specifically, the next section examines how SAPROs operate in an environment which foregrounds neoliberal notions of the state and its relation to the external environment. The analysis shows that due to a sleight of hand and the reframing of the issue, political elites are being presented with limited and alternate sets of data in the form of information subsidies, which they are asked to use to assess both the issues and CSR efforts of the funding industries.

\section{The Role of SAPROs in Neoliberalism: Valorising Notions of Individual Choice, Freedom, Choice and Economic Values}

Globally, risk industries invest significant resources in the cultural production of responsibility communications that define freedom as being in the public interest. Harvey (2005) argues that the triumph of neoliberalism has been to capture the ideals of individual freedom and turn them against intervention and regulation by the state. Certainly, the neoliberal ideals propagated in the responsibility communications of SAPROs that valorise individual freedoms and personal choice "appeal to anyone who values the ability to make decisions for themselves" (Harvey, 2005, p. 5). This triumph "had to be backed up by a practical strategy that emphasized the liberty of consumer choice, not only with respect to particular products but also with respect to lifestyles, modes of expression and a wide range of cultural practices" (Harvey, 2005, p. 42). Individual choice is the most frequently invoked determinant of risk by SAPROs that ignore the influence of global marketing. In the case of DrinkWise, individual choice extends to family choice, that parents choose the behaviors that will determine their children's drinking (Pietracatella and Brady, 2016). Rather than the state providing social protection, under the economic values of neoliberalism, social protection is a commodity that can be bought and sold on the market and it is the market that is better at providing protection. Thus, individual security becomes a matter of individual choice (Harvey, 2005, p. 168).

Personal responsibility underpins neoliberal political practice. Risk industries that focus on individual responsibility in their risk communications treat the choice to purchase a risk product as no different to any other purchase. The common "drink 
responsibly" and "gamble responsibly" slogans imply that any decision to drink or gamble irresponsibly is entirely the choice of the individual. This personal responsibility fits neatly into the neoliberal framework, as it is portrayed as freedom from intervention. The discourse that freedom from state intervention (i.e., negative freedom) is more important than personal freedom from avoidable risk (i.e., positive freedom) has become the dominant discourse, particularly in affluent countries, such as Australia and the UK. The discourse is not limited to alcohol and other risk industries and reflects the developed world's position on individual choice. According to the UK Prime Minister Tony Blair in 2006, many supposed public health problems are individual lifestyle choices: "These are not epidemics in the epidemiological sense-they are the result of millions of individual decisions, at millions of points in time" (Glasgow and Schrecker, 2015, p. 282). Ward (2009) notes that when asked about regulating the provision of fast food to children, former Australian Prime Minister Tony Abbott, who was then the Federal Minister for Health, stated "that the only people responsible for putting food in the mouths of children were the children and their parents" (Ward, 2009, p. 3). Like his UK counterpart, Blair, Abbott's statement shows that he follows "the neo-liberalist line of decreasing the regulatory powers of the State and increasing the responsibility of citizens" (Ward, 2009, p. 4).

Shifting the responsibility to the individual and targeting young people and their parents is a strategy that has been employed by alcohol SAPROs more generally (Mialon and McCambridge, 2018, p. 666). If the responsibility for young people's drinking is deemed to lie with parents, then any regulation that might interrupt the freedoms of other adults is unnecessary. By targeting a segment of the market, the case for society-wide control is undermined. Thus, the continual repetition of a framework under which youth drinking is a problem feeds into a hegemonic acceptance of a free market for alcohol. The existence of the youth drinking problem is not refuted, neither is the need for education, but alcoholrelated harms are known to be present across age groups (Babor et al., 2010).

Room (2011) argues that when applied, neoliberal ideals, including consumer sovereignty, increase alcohol consumption and that modern societies rely on sobriety. According to Room (2011, p. 141), "The ideological solution to this societal dilemma is to individualize the responsibility for handling it, apotheosizing the ideal of the moderate drinker, at the cultural level as a dream to reach for and at the individual level as an ideal of a secular pilgrim's progress." Under neoliberal conditions, individual consumers have greater agency and increased selfreliance in managing their own well-being as the state reduces their services (Ward, 2009).

The cultural production of pro-consumption responsibility communications that valorize neoliberal values by SAPROs represents a practical strategy in action. Confidential alcohol industry documents were released when Philip Morris was ordered to make tobacco documents publicly available under the US MSA (Bond et al., 2010). The documents revealed that the tobacco and alcohol industries adopted similar strategies to "develop and provide potentially counterproductive public education campaigns so as to appear socially responsible and in an effort to deflect tighter controls on product" (Bond et al., 2010, p. 329). One key area of concern considered in the documents was the future possibility of increased taxation and government regulation (Ward, 2009). Numerous strategies were proposed to prevent increased taxation with the ultimate and cumulative effect of increasing the responsibility of individuals for their alcohol consumption and any related affects (Ward, 2009).

If problems generated by risk industries must be solved primarily by the market and with minimal regulation, then problems such as dependency, chronic disease and lowered productivity become family burdens. Davies (2017) has shown that competition exerts a moral force by normalizing the idea of both winners and losers. In a neoliberal environment, those suffering harms from risk industries are the natural losers in a rational system. Through the consumption of dominant cultural texts and the assimilation of frameworks disseminated by SAPROs, citizens implicitly consent to risk industry harm; however, this is a fair outcome of competition. This construction of consent based on the discourse of freedom camouflages an increasing disparity (Harvey, 2005).

\section{THE OPERATION OF SAPROS IN A NEOLIBERAL ENVIRONMENT}

\section{Indirect Lobbying via the Dissemination of Indirect Information Subsidies}

Having considered the establishment of SAPROs as a market approach to solve the harms associated with risk products and the role of SAPROs in valorizing freedom in an environment conducive to neoliberal ideals, this article now examines the mechanics affecting this process. Risk industries influence policy makers indirectly through various intermediary organizations. Such organizations act with varying degrees of self-interest, which they may or may not state. For example, in representative peak bodies and trade associations, policy actors are cognizant that they advocate for funding industries or subscribers. When an interest group provides information subsidies to policy actors on behalf of another organization, these information subsidies are equivalent to Gandy's (1982) concept of indirect information subsidies.

The provision of indirect information subsidies functions as an indirect form of lobbying. Indirect lobbying is mostly informational and usually involves supplying information to policy actors who are also influenced indirectly by the mobilization of public opinion. According to this conception of indirect lobbying, the media relations of grassroots organizations, real or fake, can be used as a PR tool to indirectly influence policy actors. However, conceptions of indirect lobbying are changing. Trapp and Laursen (2017, p. 143) found that influencing the public as actors in the policy process through direct communications may not be the goal of grassroots strategies as was once thought. Given the increasing medicalization of politics, policy makers as media consumers are the probable targets of politically motivated media communications. Walker (2012, p. 561) hypothesizes that organizations with heavy public presences 
and those concerned with negative public impacts will seek to influence the public to achieve the legitimation to operate. $\mathrm{He}$ states: "in such cases, lobbying itself is a PR strategy directed both at the public and at legislators and government agencies" (Walker, 2012; p. 567).

Gandy's (1982) concept of information subsidies is useful in understanding how interest group lobbying occurs and how communications by SAPROs can be considered a form of indirect lobbying. Information subsidies reduce the cost of gathering and processing the information that decision makers in the policy system use to develop the policies that will benefit their individual (or sometimes group) welfare. Indirect information subsidies are delivered to other participants or policy actors in the policy process via news reports, scientific publications, legislative investigations and court testimonies, all of which are perceived to be relatively objective channels of influence (Gandy, 1992). The delivery of information subsidies coupled with framing are components of the media relations process of agenda building. These powerful tools can be accessed in a diversified and modern media environment. The view taken in this article is that controlling the information environment is central to achieving the political objectives of risk industries. Somewhat removed from their funders by their independent structures, SAPROs such as DrinkWise provide a convenient means for presenting politically expedient information. Information is presented to policy actors on behalf of risk industries, which are viewed as low-credibility sources of health information, in the form of information subsidies.

Two extant studies on alcohol SAPROs (Carah and van Horen, 2011; Pietracatella and Brady, 2016) used DrinkWise media releases as data to analyse the media relations activities of DrinkWise as a form of indirect lobbying. Carah and van Horen (2011) also analyzed the newspaper stories generated by the media releases. The research showed that the "cherry picking" of information or the emphasizing of certain characteristics at the expense of others helps to define and frame issues to suit organizational agendas. Carah and van Horen (2011) also found that despite findings from DrinkWise's own commissioned research that implicated the alcohol industry in constructing and reinforcing the drinking culture, their information subsidies failed to address this and instead promoted drinking culture aspects that aligned with the framework they presented.

DrinkWise has sponsored attitudinal and academic research that subsidized political decision makers, who may not have had the resources to conduct their own research. Doing so, allows DrinkWise to select and contextualize the information gathered to benefit the organization and its funders (Pietracatella and Brady, 2016, p. 63). DrinkWise framed issues of alcohol harm as a cultural problem and portrayed drinkers as young (Carah and van Horen, 2011). DrinkWise expressed a judgement that drinking was learned from parents and offered its organization as a solution for developing a better drinking culture via the education of parents. Pietracatella and Brady (2016) also found that the DrinkWise media relations discourse promoted targeted solutions by the separation of the population into responsible and irresponsible drinkers. Newspaper reports considered DrinkWise to be a legitimate contributor to the debate; however, criticisms by health researchers appear not to have destabilized the DrinkWise frame or the organization (Carah and van Horen, 2011). It is this sustained and targeted framing by SAPROs that indirectly influences populations and policy actors who, upon receiving these indirect information subsidies and feeling sympathetic to DrinkWises's framing of the problem, would find it hard to support society-wide legislation that unfairly discriminates against responsible drinkers.

Both studies showed that DrinkWise frames issues to create a favorable agenda for the alcohol industry. Pietracatella and Brady (2016) found that the general practice of DrinkWise media relations was intended to disseminate politically motivated messages to elite individuals and policy makers due to $60 \%$ of the messages identified in the media release sample being directed to this stakeholder group (58). This occurred despite parents being the said targets of the ongoing social marketing campaign that was conducted during the timeframe of the media release sample. These findings support those of Trapp and Laursen (2017) on interest groups that showed that policy makers were the targets of media relations and not the general public. Carah and van Horen (2011, p. 10) found evidence of the scope, skill and resources of DrinkWise media relations by applying their sophisticated understanding of the news template. It should be noted that DrinkWise's media releases form an indirect information subsidy to journalists and policy makers consuming media; however, media relations activities formed only a part of their overall mediated activities. A sustained general public facing campaign resembling public service announcements successfully shifted the onus from industry responsibility to parents as being responsible for their children's learned behavior (Pietracatella and Brady, 2016). This approach has succeeded in holding back threatened government regulation. Miller et al. (2011) examined submissions concerning alcohol made to the Australian National Preventative Health Taskforce (NPHT) discussion paper; Australia, the healthiest country by 2020. All alcohol industry submissions mentioned Drinkwise, and supported the industry-friendly campaigns carried out by Drinkwise over recommended regulatory interventions such as higher taxes on alcohol (Miller et al., 2011).

\section{Filling the Credibility Deficit}

The revelation of their vested interest means that alcohol SAPROs have a credibility deficit that must be managed if their information subsidies are to retain any value among their intended recipients (Gandy, 1992). One way of filling the credibility deficit created by the revelation of its vested interest is for the alcohol industry to position SAPROs as acting in the public interest. When expedient, SAPROs go to great lengths to claim independence from sponsoring industries in order to project an unbiased public interest role of delivering responsibility messages and alcohol education. According to its website (DrinkWise, 2018), DrinkWise is an "independent, not-for-profit organization" that focuses on bringing about "a healthier and safer drinking culture in Australia." SAPROs have taken full advantage of a climate that demands CSR and have effectively subverted it to serve their funding interests. Alternatively, when expedient, SAPROs use the notion of CSR 
to fill the credibility gap that the revelation of their being industry-funded creates. In Australia, DrinkWise's public interest posturing is strengthened by the CSR and philanthropy claims it makes in its alcohol industry submissions to the government. Due to the early limited government funding DrinkWise received, such claims need to be made to show DrinkWise's legitimacy and credibility (Miller et al., 2011).

Following the revelation of who funded them, alcohol SAPROs made a number of claims to fill the resulting credibility deficit, including that: (1) SAPROs function to perform a public interest service; (2) SAPROs are independently structured; (3) the board members of SAPROs comprise individuals of personal credibility; and (4) SAPROs are endorsed by third parties and the government (Pietracatella and Brady, 2016). These claims reflect the credibility-building techniques used by all third-party organizations and groups with undisclosed funders. Due to the revelation of industry funding, SAPROs involvement in policy debates depends on the excessive employment of credibilitybuilding PR techniques.

\section{The Appearance of Self-Regulation}

The revelation that SAPROs are industry funded not only allows industries to claim CSR, but also grants them the appearance of functioning as "independent" regulatory bodies. This provides freedom for both consumers and those in the industry, as freedom in the neoliberal sense is equated with an absence of imposed external and authoritarian constraints on the individual (Ives, 2015). Hawkins and Holden (2014, p. 66) note that SAPROs use "their apparent ability to implement policy initiatives on behalf of the government, often in place of mandatory regulation" to position themselves as partners in the policy process. However, SAPROs create another level of bureaucracy, and interestingly, alcohol SAPROs mimic the work of credible government departments.

Former politicians and bureaucrats are often installed as the chairpersons of SAPROs. In accepting such positions, they not only convey community and public interest in SAPROs, but also lend their personal credibility to the organization (Miller et al., 2011, p. 1561). Governments are not completely impartial either. As discussed above, the reliance of governments on what has been termed the "addiction surplus" revenue derived from tobacco, alcohol and gambling gives them a vested interest in SAPROs (Adams and Livingstone, 2015; Adams, 2016). SAPRO boards and management teams may also comprise members who have previously worked for the government, risk industries and not-for-profit organizations (e.g., GambleAware in the UK). In addition to their past and future lobbying use, public figures in SAPROs provide credibility to the organizations, which allows them to retain their value. Credibility through thirdparty endorsement is paramount to SAPROs. It grants further opportunities for positive media relations and inflated media impressions. Both DrinkWise and DrinkAware have received advertising and PR awards that they have used in further media communications to legitimize their activities.

The perception of self-regulation and harm minimization on a global level is the purview of the International Alliance for Responsible Drinking (IARD). The IARD (formerly known as the International Center for Alcohol Policies) has been styled as a shadow WHO unit for alcohol (Babor and Robaina 2013); however, its funding is considerably superior to that of the WHO. This international SAPRO focuses on alcohol control policies, medical research, and alcohol education. By posing as health organizations, SAPROs can use the full weight of their substantial budgets to directly challenge public health issues. The conflict of their vested interest undermines the public good that they claim to represent and falls short of their CSR claims. SAPROs are a highly publicized concession made by industry.

SAPROs are positioned to negotiate on behalf of their risk industries. They produce cultural texts in the form of media releases and marketing campaigns that may make minor concessions, but aim to maintain the status quo (e.g., SAPROs may admit to alcohol-related harms, but they attribute such harms to personal choices). Even when the long-term effects of alcohol consumption are acknowledged (e.g., dependency and chronic disease), the solutions are presented as being the responsibility of individuals or families and the role of SAPROs is to empower individuals. The Australian SAPRO DrinkWise was founded in 2005 , the same year as the deregulation of the labor market and after nearly a decade of conservative government in Australia (Boucher and Sharpe, 2008). The development of SAPROs is both a consequence and affirmation of neoliberalism. The negative aspects of neoliberalism must be "seen" to be managed to ensure continued public consent to neoliberal policies. SAPROs perform the necessary inflated PR activities that seek to achieve this objective on behalf of industries and governments.

\section{ARE SAPROS A SPECIAL TYPE OF FRONT GROUP?}

To be considered front groups, SAPROs would need to conceal their funding and or purpose. As SAPROs do not conceal their industry funding, they do not conform to Fitzpatrick and Palenchar (2006) definition of a front group as a group that conceals it's funding. This also means they have no fear of being "outed," as exposure of front group interests can result in a loss of credibility and effect their ability to influence on public policy (Bodensteiner, 1997). The only other way in which SAPROs could be considered front groups is if they were found to be obscuring their purposes or intentions, as another definition of a front group is "an organization that purports to represent one agenda while in reality it serves some other interest whose sponsorship is hidden or rarely mentioned" (The Center for Media and Democracy, 2013: para 1). While their intention and direction is likely obscured but funding not hidden, SAPROs present their risk industries as beneficent, knowledgeable and socially responsible.

Associations, such as the International Public Relations Association, do not prohibit the use of front groups; however, deception and deceptive practices are prohibited. Some practitioners interpret the code of conduct to mean they must reveal the identity of the organizations they serve only if they 
are asked to do so and not all practitioners are bound to professional organizations (Fitzpatrick and Palenchar, 2006, p. 221). Due to a perceived conflict of interest, tobacco, alcohol and gambling producers who are interested in profits and who wish to avoid inhibitory regulation use front groups to provide politicians with information subsidies that will help them to be re-elected. SAPROs use the media to transfer public opinion research to policy makers, cherry picking polls and highlighting quotable opinions that journalists cannot ignore; fulfilling the objectives of political PR, of persuading and informing audiences.

Policy actors "will invest in the production of influence as long as the benefits they expect to receive from government policy exceed the costs of influencing that policy" (Gandy, 1982, p. 49). Savell et al. (2014) found that tobacco industry groups frequently engage in indirect lobbying that obscures their interests or their purposes. For example, the Ventilation Task Force, funded by Phillip Morris, stated that its aim was to reduce workplace harm from second-hand smoke; however, its real aim, as revealed by the US MSA documents, was to delay smoking bans (Adams, 2016). The policy set relied on the information subsidies provided by these front groups. Front groups apply controversial PR techniques that work. An outing of interests clearly identifies front group activities; however, front groups may adopt sophisticated tactics to obscure their purpose and thus may not be easily identifiable to the public or policy makers.

Front groups can be distinguished from other manifestations of interest groups or intermediaries by their level of transparency in relation to their interests and purposes. Legitimate grassroots lobbying groups and issue advocacy campaigns do not engage in deception (Fitzpatrick and Palenchar, 2006, p. 206). Only critical appraisal can reveal whether the interests being advanced by organizations truly respond to societal threats and whether the CSR and public interest claims made are sincere or tactical. Current research suggests that SAPROs obscure their purposes and intentions to protect risk industries from further regulatory legislation by bolstering their direct lobbying with indirect lobbying activities (Pietracatella and Brady, 2016). However, it should be noted that the average consumer responding to the face value of CSR campaigns disseminated through SAPROs is unlikely to understand the underlying intention. Campaigns that conceal their true purpose are "stealth campaigns." Such campaigns engage in systematic efforts to deceive individuals by using carefully chosen names to mask their real interests and serve a very different agenda to that which they appear to serve (Pfau et al., 2007, p. 74).

Thus, SAPROs are sophisticated front groups that may reveal their funding but obscure their intentions and represent a new development in industry front groups and corporate political action. Different industries use SAPROs to indirectly subsidize governments with the information necessary to form policies in relation to issues arising from the use of their products that will benefit the industry. They do this by declaring (rather than concealing) their interests. Surprisingly, despite the revelation of their interests, such fronts continue to work. The provision of this type of indirect information subsidy by SAPROs may be necessary to the perpetuation of neoliberal policies.

\section{CONCLUSION}

Concerns about the communication practices of risk industries are long standing. Researchers generally refer to such activities as CSR and have found that the tobacco and alcohol industries engage in similar activities in an attempt to affect legislation at the expense of public health. This article sought to highlight a new development in the strategies of front groups. It showed that traditional delegitimizing agents or the potential outing of funding interests have been neutralized by SAPROs' upfront pronouncements and their subsequent attributions of those interests to CSR. The key development in the third-party technique adopted by SAPROs has been their capacity to fill the credibility deficit created by revelations about their funding interests. To continue to engage in indirect lobbying, SAPROs have to work harder than previous groups to fill the gap this revelation creates. However, as Adams (2016) argues, the billions of dollars of surplus profits generated by problem and harmful consumption provides an ample means to deploy strategic PR to prevent its loss. If such funding was not available or at stake, SAPROs may not be considered viable influence-producing machines that can be employed to maintain neoliberalism.

This article revealed a research deficit. Specifically, it showed that further attention needs to be directed toward the communication of risk industries and their political PR activities. It also identified a relationship between neoliberalism and this new development in front group tactics. Neoliberal ideology enacted by corporations and states reshapes society around neoliberal ideals. The promotion and enactment of neoliberal practices provides a sympathetic policy environment and an increased sensitivity to risk has contributed to this development in PR tactics. Deregulation has created a space for industries to respond with CSR. CSR-like campaigns have spurred an opportunistic shift in governance from democratic structures to organizations, such as SAPROs, which have unprecedented power and influence. SAPROs define public interest in terms of neoliberalism. The emphasis on personal responsibility, rather than health consequences ensures that any action they take is benign and non-invasive. Examples in this article have been drawn primarily from the alcohol industry; however, SAPROs, also operate in the tobacco and sugar industries and attention should be paid to their growing presence in the gambling industry.

One limitation of this article is that a lack of previous research made it difficult to draw satisfactory conclusions about the indirect lobbying activities of risk industries. Future research should seek to analyse SAPROs empirical content. Such research could make multiple contributions to the PR discipline and inform public policy more widely. This study also raised a number of important ethical issues and questions about whether normative PR models contribute to 
societal problems. SAPROs flourish in a neoliberal policy environment. Due to their discursive functions, SAPROs have been protected from being viewed negatively as front groups. This growing strand of opaque PR practices (whereby organizations advocate on behalf of industries with contentious agendas) has the potential to affect deliberative public debate and policy decisions. If $\mathrm{PR}$ is considered the armor of the

\section{REFERENCES}

Adams, P. J. (2016). Moral Jeopardy: Risks of Accepting Money from the Alcohol, Tobacco and Gambling Industries. Cambridge, UK: Cambridge University Press. doi: 10.1017/CBO9781316118689

Adams, P. J., and Livingstone, C. (2015). Addiction surplus: the add-on margin that makes addictive consumptions difficult to contain. Int. J. Drug Policy 26, 107-111. doi: 10.1016/j.drugpo.2014.07.018

Anderson, P. (2004). The beverage industry's social aspects organizations: a public health warning. Addiction 99, 1376-1377. doi: 10.1111/j.1360-0443.2004.00866.x

Apollonio, D. E., and Bero, L. A. (2007a). The creation of industry front groups: the tobacco industry and 'get government off our back'. Am. J. Public Health 97, 419-427. doi: 10.2105/AJPH.2005.081117

Apollonio, D. E., and Bero, L. A. (2007b). Industry front groups: a tobacco case study. J. Verbraucherschutz Lebensmittelsicherheit 2, 341-348. doi: 10.1007/s00003-007-0205-8

Avery, M. R., Droste, N., and Giorgi, C. (2016). Mechanisms of influence: alcohol industry submissions to the inquiry into fetal alcohol spectrum disorders. Drug Alcohol Rev. 35, 665-672. doi: 10.1111/dar.12399

Babor, T. F. (2009). Alcohol research and the alcoholic beverage industry: issues, concerns and conflicts of interest. Addiction 104(Suppl. 1), 34-47. doi: 10.1111/j.1360-0443.2008.02433.x

Babor, T. F., Caetano, R., and Casswell, S. (2010). Alcohol: No Ordinary Commodity - Research and Public Policy. Oxford: Oxford University Press.

Babor, T. F., and Robaina, K. (2013). Public health, academic medicine, and the alcohol industry's corporate social responsibility activities. Am. J. Public Health 103, 206-214. doi: 10.2105/AJPH.2012.300847

Babor, T. F., Robaina, K., and Brown, K. (2018). Is the alcohol industry doing well by 'doing good'? Findings from a content analysis of the alcohol industry's actions to reduce harmful drinking. BMJ Open. 8:e024325. doi: 10.1136/bmjopen-2018-024325

Biebricher, T. (2015). Neoliberalism and democracy. Constellations 22, 255-266. doi: $10.1111 / 1467-8675.12157$

Bodensteiner, C. A. (1997). Special interest group coalitions: Ethical standards for broad-based support efforts. Public Relat. Rev. 23, 31-46. doi: 10.1016/S0363-8111(97)90004-7

Bond, L., Daube, M., and Chikritzhs, T. (2010). Selling addictions: similarities in approaches between Big Tobacco and Big Booze. Aust. Med. J. 3, 325-332. doi: 10.4066/AMJ.2010.363

Boucher, G., and Sharpe, M. (2008). The Times Will Suit Them: Postmodern Conservatism in Australia. Crows News, QLD: Allen and Unwin.

Brownell, K. D., and Warner, K. E. (2009). The perils of ignoring history: Big tobacco played dirty and millions died. How similar is big food? Millbank Q. 87, 259-294. doi: 10.1111/j.1468-0009.2009.00555.x

Carah, N., and van Horen, A. (2011). Drinkwise, enjoy responsibly: News frames, branding and alcohol. Media International Australia Incorporating. Cult. Policy 141, 5-16. doi: 10.1177/1329878X1114100103

Cowlishaw, S., and Thomas, S. L. (2018). Industry interests in gambling research: lessons learned from other forms of hazardous consumption. Addict. Behav. 78, 101-106. doi: 10.1016/j.addbeh.2017.11.007

Davies, W. (2017). The Limits of Neoliberalism: Authority, Sovereignty and the Logic of Competition. Los Angeles, CA: Sage.

Dowling, J., and Pfeffer, J. (1975). Organizational legitimacy: Social values and organizational behavior. Pac. Soc. Rev. 18, 122-136. doi: 10.2307/1388226

DrinkWise (2018) About DrinkWise. Available online at: https://drinkwise.org.au/ about-us/about/\# (accessed September 17, 2018). establishment, SAPROs represent an advanced weapon of risk industries.

\section{AUTHOR CONTRIBUTIONS}

All authors listed have made a substantial, direct and intellectual contribution to the work, and approved it for publication.

Fitzpatrick, K. R., and Palenchar, M. J. (2006). Disclosing special interests: constitutional restrictions on front groups. J. Public Relat. Res. 18, 203-224. doi: 10.1207/s1532754xjprr1803_1

Gandy, O. H. (1982). Beyond Agenda Setting: Information Subsidies and Public Policy. Norwood, NJ: Ablex Publishing Company.

Gandy, O. H. (1992). "PR, and public policy: the structuration of dominance in the information age," in Rhetorical and Critical Approaches to Public Relations, eds E. Toth and RL Heath (Hilldale, NJ: Lawrence Erlbaum Associates), 131-164.

Garriga, E., and Mele, D. N. (2004). Corporate social responsibility theories: mapping the territory. J. Bus. Ethics 53, 51-71. doi: 10.1023/B:BUSI.0000039399.90587.34

Glasgow, S., and Schrecker, T. (2015). The double burden of neoliberalism? Noncommunicable disease policies and the global political economy of risk. Health Place 34, 279-286. doi: 10.1016/j.healthplace.2015. 06.005

Grayson, D., and Nelson, J. (2013). Corporate Responsibility Coalitions: The Past, Present, and Future of Alliances for Sustainable Capitalism. Palo Alto, CA: Stanford University Press.

Hall, W. D., and Room, R. (2006). Assessing the wisdom of funding DrinkWise. Med. J. Aust. 185, 635-636. doi: 10.5694/j.1326-5377.2006.tb00736.x

Harvey, D. (2005). A Brief History of Neoliberalism. New York, NY: Oxford University Press.

Hawkins, B., and Holden, C. (2014). 'Water dripping on stone'? Industry lobbying and UK alcohol policy. Policy Politics 42, 55-70. doi: 10.1332/030557312X655468

Houghton, E. (1998). A comparative analysis of alcohol education programs sponsored by the beverage alcohol industry. J. Alcohol Drug Educ. 43, 15-33.

Ingenhoff, D., and Marschlich, S. (2019). Corporate diplomacy and political CSR: Similarities, differences and theoretical implications. Public Relat. Rev. 45, 348-371 doi: 10.1016/j.pubrev.2019.01.002

Ives, A. (2015). Neoliberalism and the concept of governance: Renewing with an older liberal tradition to legitimate the power of capital. Mémoire(s), Identité(s) et Marginalité(s) dans le Monde Occidental Contemporain 14. doi: 10.4000/mimmoc. 2263

Kerr, C. (2009). Alcohol Shock-ads Missing the Mark. The Australian. Available at: https://www.theaustralian.com.au/news/health-science/alcohol-shock-adsmissing-the-mark/news-story/1f828ac964a60dd721c36f7f6bad0661

Kinderman, D. (2011). 'Free us up so we can be responsible!' The co-evolution of corporate social responsibility and neo-liberalism in the UK, 1977-2010. Soc. Econ. Rev. 10, 29-57. doi: 10.1093/ser/mwr028

Kinderman, D. (2015). "Explaining the rise of national corporate social responsibility: the role of global frameworks, world culture, and corporate interests," in Corporate Social Responsibility in a Globalizing World. K. Tsutsui and A. Lim (New York, NY: Cambridge University Press), 107-146. doi: 10.1017/CBO9781316162354.004

L'Etang, J. (1994). Public relations and corporate social responsibility: Some issues arising. J. Bus. Ethics 13, 111-123. doi: 10.1007/BF00881580

McCambridge, J., Kypri, K., and Miller, P. (2014). Be aware of Drinkaware. Addiction 109, 519-524. doi: 10.1111/add.12356

McDaniel, P. A., Intinarelli, G., and Malone, R. E. (2008). Tobacco industry issues management organizations: creating a global corporate network to undermine public health. Glob. Health 2:4. doi: 10.1186/1744-8603-4-2

Mialon, M., and McCambridge, J. (2018). Alcohol industry corporate social responsibility initiatives and harmful drinking: a systematic review. Eur. J. Public Health 28, 664-673. doi: 10.1093/eurpub/cky065

Miller, D., Harkins, C., and Schlögl, M. (2018). Impact of Market Forces on Addictive Substances and Behaviours: The Web of Influence 
of the Addictive Industries. Oxford: Oxford University Press. doi: 10.1093/acprof:oso/9780198753261.001.0001

Miller, N. (2009). Here's Jeers! Sydney Morning Herald. Available online at: https:// www.smh.com.au/national/heres-jeers-20091204-kb2e.html (accessed April 9, 2020).

Miller, P. G., de Groot, F., and McKenzie, S. (2011). Vested interests in addiction research and policy. Alcohol industry use of social aspect public relations organizations against preventative health measures. Addiction 106, 1560-1567. doi: 10.1111/j.1360-0443.2011.03499.x

Miller, P. G., Kypri, K., and Chikritzhs, T. N. (2009). Health experts reject industry-backed funding for alcohol research. Med. J. Aust. 190, 713-714. doi: 10.5694/j.1326-5377.2009.tb02647.x

Petticrew, M., Maani Hessari, N., Knai, C., and Weiderpass, E. (2018a). How alcohol industry organisations mislead the public about alcohol and cancer. Drug Alcohol Rev. 37, 293-303. doi: 10.1111/dar.12596

Petticrew, M., Maani Hessari, N., Knai, C., and Weiderpass, E. (2018b). The strategies of alcohol industry SAPROs: inaccurate information, misleading language and the use of confounders to downplay and misrepresent the risk of cancer. Drug Alcohol Rev. 37, 313-315. doi: 10.1111/dar.12677

Pfau, M., Haigh, M. M., and Sims, J. (2007). The influence of corporate front-group stealth campaigns. Commun. Res. 34, 73-99. doi: 10.1177/0093650206296083

Pietracatella, R. J., and Brady, D. (2016). Drink wisely Australians, but keep drinking: does the alcohol industry in Australia frame the discourse on alcohol to maintain hegemony? Media Int. Aust. 160, 53-66. doi: $10.1177 / 1329878 \times 16651136$

Room, R. (2011). Addiction and personal responsibility as solutions to the contradictions of neoliberal consumerism. Crit. Public Health 21, 141-151 doi: 10.1080/09581596.2010.529424

Savell, E., Gilmore, A. B., and Fooks, G. (2014). How does the tobacco industry attempt to influence marketing regulations? A systematic review. PLoS ONE 9:e87389. doi: 10.1371/journal.pone.0087389

Scherer, A. G., and Palazzo, G. (2011). The new political role of business in a globalized world: a review of a new perspective on CSR, and its implications for the firm governance, and democracy. J. Manage. Stud. 48, 899-931. doi: $10.1111 / j .1467-6486.2010 .00950 . x$

Strömbäck, J., and Kiousis, S. (Eds.). (2011). Political Public Relations: Principles and Applications. New York, NY: Routledge. doi: 10.4324/9780203864173
Sweet, M. (2009). Some Questions About the Independence of DrinkWise. Crikey. Available online at: https://blogs.crikey.com.au/croakey/2009/05/28/somequestions-about-the-independence- of-drinkwise/ (accessed April 9, 2020).

The Center for Media and Democracy (2013) SourceWatch: Front groups. The Center for Media and Democracy. Available online at: https://www. sourcewatch.org/index.php/Front_groups (accessed May 23, 2018).

Thorson, D. (2010). The neoliberal challenge: what is neoliberalism? Contemp. Read. Law Soc. Justice 2, 188-214.

Trapp, N. L., and Laursen, B. (2017). Inside out: Interest groups' 'outside' media work as a means to manage 'inside' lobbying efforts and relationships with politicians. Interest Groups Advocacy 6, 143-160. doi: 10.1057/s41309-017-0016-y

Turnbull, N. (2014). "Social marketing: drinkwise Australia," in Public Relations Campaigns, eds M. Sheehan and R. Xavier (Melbourne, VIC: Oxford University Press), 86-103.

Walker, E. T. (2012). Putting a face on the issue: Corporate stakeholder mobilization of professional grassroots lobbying campaigns. Bus. Soc. 51, 561-601. doi: 10.1177/0007650309350210

Ward, P. R. (2009). The alcohol industry, neo-liberalism and the political economy of health. Aust. Med. J. 1, 1-6. doi: 10.4066/AMJ.2 009.51

Williams, R. A., and Perraut, A. (2008). Facilitated Market Solutions for Social Problems. George Mason University, Mercatus Centre. Available online at: https://www.mercatus.org/system/files/WP0831_RSP_Facilitated_Market_ Solutions_for_Social_Problems.pdf (accessed April 9, 2020).

Conflict of Interest: The authors declare that the research was conducted in the absence of any commercial or financial relationships that could be construed as a potential conflict of interest.

Copyright (๑) 2020 Pietracatella and Brady. This is an open-access article distributed under the terms of the Creative Commons Attribution License (CC BY). The use, distribution or reproduction in other forums is permitted, provided the original author(s) and the copyright owner(s) are credited and that the original publication in this journal is cited, in accordance with accepted academic practice. No use, distribution or reproduction is permitted which does not comply with these terms. 